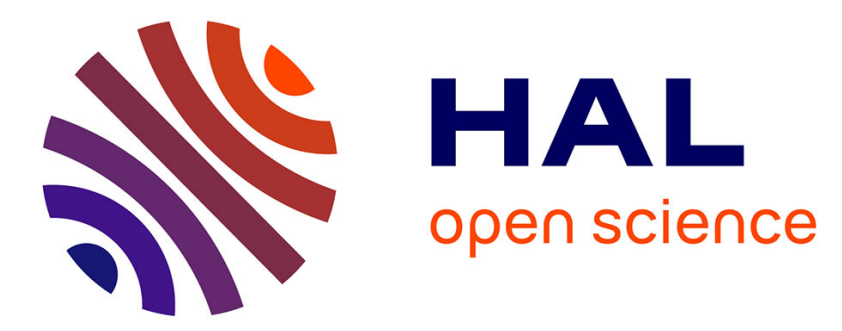

\title{
Evaluation of the Effectiveness of Modern TRIZ Based on Practical Results in New Product Development
}

\author{
Oleg Y. Abramov, Alexander V. Medvedev, Vladimir Y. Rychagov
}

\section{To cite this version:}

Oleg Y. Abramov, Alexander V. Medvedev, Vladimir Y. Rychagov. Evaluation of the Effectiveness of Modern TRIZ Based on Practical Results in New Product Development. 19th International TRIZ Future Conference (TFC), Oct 2019, Marrakesh, Morocco. pp.36-44, 10.1007/978-3-030-32497-1_4 . hal-02905549

\section{HAL Id: hal-02905549 \\ https://hal.inria.fr/hal-02905549}

Submitted on 23 Jul 2020

HAL is a multi-disciplinary open access archive for the deposit and dissemination of scientific research documents, whether they are published or not. The documents may come from teaching and research institutions in France or abroad, or from public or private research centers.
L'archive ouverte pluridisciplinaire HAL, est destinée au dépôt et à la diffusion de documents scientifiques de niveau recherche, publiés ou non, émanant des établissements d'enseignement et de recherche français ou étrangers, des laboratoires publics ou privés. 


\title{
Evaluation of the Effectiveness of Modern TRIZ Based on Practical Results in New Product Development
}

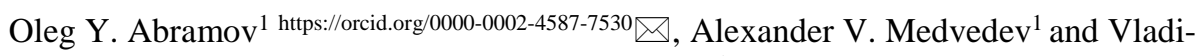 \\ mir Y. Rychagov ${ }^{1}$ \\ ${ }^{1}$ Algorithm Ltd., 16 Ruzovskaya Street, St. Petersburg, 190013, Russia \\ Oleg.Abramov@algo-spb.com
}

\begin{abstract}
Today's innovation processes used in industry are generally inefficient: various sources indicate that only one out of three-thousand, raw ideas yield a commercial product. Fortunately, most of the ideas are quickly rejected before much time and money are spent on their development. Still, approximately 300 of the raw ideas are normally selected for further investigation and development, which results in launching around 125 small pilot projects and in other time and money-consuming activities - all for the sake of a single commercially successful product. TRIZ-practitioners claim a much higher efficacy with the TRIZbased innovation process because TRIZ provides a more systematic approach for innovation and dramatically speeds up the new product development (NPD) process. A number of case studies using TRIZ for NPD back up this statement; however, there is so far no solid quantitative data available to support this statement. In this paper, the authors have tried to evaluate the effectiveness of modern TRIZ in NPD by analyzing a pool of technical solutions for new products developed for different companies in actual TRIZ-consulting projects. For each solution, the authors have tried to identify whether the new product was ultimately launched. This analysis revealed the number of solutions/ideas that TRIZ consultants developed in order to launch one new product and the percentage of successful projects. The results show that using TRIZ improves the efficiency of the NPD process from about 5 to 12 times, which confirms that TRIZ brings high value to NPD.
\end{abstract}

Keywords: innovation funnel, new product development, NPD, Quantum Economic Analysis, QEA, TRIZ.

\section{Introduction}

Today's innovation process is known to be quite a wasteful practice for businesses. For example, Stevens and Burley [1] indicate that, on average, in order to obtain one commercially successful product about 3000 raw ideas are typically generated and almost all of these ideas are then rejected in the new product development (NPD) process. This innovation process, or innovation funnel, includes the following steps [1]:

- About 3000 raw ideas are generated and internally screened,

- Approximately 300 of these ideas are then submitted to decision makers, 
- About 125 ideas are further developed in small projects / small efforts,

- On average, only 1.7 of those ideas result in product launch,

- Just one of the launched products is commercially successful.

Other authors indicate similar numbers characterizing the efficacy of the innovation funnel. For example, Staube in his post [2] indicates that out of 95 projects aimed at incremental innovations, just one results in launching a product, which is not necessarily commercially successful. These figures are nearly comparable to Stevens and Burley's data that 125 small-scale projects yield 1.7 launched products.

The common perception is that in order to increase the probability of obtaining a commercially successful product it is necessary to generate more ideas, the more the better. For example:

- In Design Thinking, as Dam and Siang [3] pointed out, "the goal is to generate a large number of ideas - ideas that potentially inspire newer, better ideas - that the team can then cut down into the best, most practical and innovative ones."

- The Systematic Inventive Thinking (SIT) approach by Boyd and Goldenberg [4] is also based on generating a multitude of creative ideas, but in this case the ideas are generated 'inside the box' just because "...the density of creative ideas is higher inside than outside."

In contrast, TRIZ offers a different way to improve the efficacy of the NPD process: generate fewer - but better and more targeted -ideas, as provided by the TRIZ-assisted Stage-Gate process [5]. The efficacy of TRIZ as a problem solving and problem finding methodology is confirmed in numerous papers, for example by Filmore and Thomond [6], Harlim and Belski [7].

Many case studies confirming the effectiveness of TRIZ have been published [8 11]. The case studies, however, represent only anecdotal data that illustrate how useful TRIZ is in solving technical problems, but do not disclose how many (if any) of the solutions obtained using TRIZ yielded commercially successful products. This leaves room for skepticism and questions about the effectiveness of TRIZ in terms of practical results for business.

For example, Ilevbare, Phaal, Probert et al. clearly expressed a common attitude toward TRIZ in their report [12]: "it appears to pay little attention to linking the inventive problems and their solutions to market needs and drivers. Therefore there exists the unpleasant possibility of TRIZ providing a solution to a problem which has little or no profitability or commercial benefit to an organization."

It should be said that such skepticism seems to be relevant for the older, "classical" TRIZ that utilizes only Altshuller's Contradiction Matrix, SU-Field Analysis and ARIZ, while modern TRIZ has tools such as Voice of the Product (VOP) [13] and Main Parameters of Value (MPV) Analysis [14,15] to address business needs better.

In a recent conference paper [16], the authors presented solid quantitative data on the effectiveness of the modern TRIZ innovation funnel and contrasted it to that described by Stevens and Burley [1]. The data, derived by a statistical analysis of the outcomes of 161 actual TRIZ consulting projects in which the authors were involved, 
confirms that modern TRIZ is approximately ten times more efficient in NPD than the traditional approach researched by Stevens and Burley.

There are, however, researchers who believe that Stevens and Burley's data, obtained 22 years ago, is obsolete because the NPD process has become much more efficient due to advances in computer power and accessibility of information. Nevertheless, NPD has not become more efficient because, as practice shows, while these factors have indeed speeded up innovations, the level of wastefulness has changed little: in order to launch one commercially successful product, thousands of raw ideas must still be generated and hundreds of small projects performed.

In this paper, the authors aim to (1) refine the data on modern TRIZ efficacy by collecting more statistical information and (2) estimate the practical potential for further improvement of TRIZ effectiveness in the NPD process by using the Quantum Economic Analysis-based screening tool (further: QEA-screening) introduced and validated by Abramov et al. [17, 18].

\section{$2 \quad$ Method}

Just as in the previous paper [16], the authors statistically analyzed the outcomes of actual TRIZ-consulting projects in which they were involved.

The analysis includes the following steps:

1. Out of a pool of completed projects, only those aimed at NPD or at developing/improving a new technology for manufacturing an existing product were selected for further analysis. Projects that were a continuation of some previous project and aimed at developing the same product were not analyzed.

2. The outcomes of each selected project were identified: (1) the number of solutions/ideas submitted to the client after the problem solving stage of the project; (2) the number of solutions further developed (e.g. substantiation, prototyping or patenting efforts); (3) whether any of these solutions eventually yielded a launched product ("successful solutions"); (4) whether any of these solutions were rejected by the client ("unsuccessful solutions").

3. Percentages of successful solutions and projects (those that yielded launched products) were calculated.

4. The locations of all successful and unsuccessful solutions within the QEA business cube were determined - as was done previously by Abramov et al. [18].

The authors wish to make the following comments regarding this procedure:

- The number of raw ideas generated in each project could not be identified because (1) the TRIZ-based methodology used in these projects does not assume using brainstorming, SIT or other techniques for generating raw ideas and, therefore, (2) the raw ideas randomly generated in the projects were not documented.

- Since all of the projects analyzed are small (typically 8-12 weeks), they can be considered equivalent to the 'small projects' in Stevens and Burley's paper [1]. 
- It was not possible to identify just how many of the launched products were commercially successful because clients are not always willing to share this sensitive information.

\section{$3 \quad$ Results}

In this research the authors analyzed a pool of 178 TRIZ-consulting projects, which they carried out from 1994 through 2018. All of these projects were performed for different clients representing a variety of industries; all of them were aimed at NPD or at developing a new technology for manufacturing an existing product. In all projects the TRIZ-assisted Stage-Gate process [5] was employed.

Of the 178 projects in the pool, 40 were actually a continuation of one of the other 138 projects. That is, these 40 were aimed at further developing solutions generated in one of the 138 initial projects. For this reason, only these 138 initial ideation projects were extracted for further analysis.

The projects analyzed have, in total, yielded 1125 feasible technical solutions that were delivered to the clients after the problem solving stage.

Only 192 of these solutions were selected by the clients and further developed at the substantiation stage of the projects, which means that some 'small efforts' were put into them (e.g. proof-of-principle prototyping or patenting).

Of this number, the authors were only able to trace the fate of 70 solutions because clients seldom gave feedback on whether the solutions delivered to them were actually implemented. These 70 solutions include:

- 32 successful solutions (i.e. those actually implemented in launched products), and

- 38 unsuccessful solutions; that is, they were either abandoned by the clients or the clients tried to implement them, but did not succeed.

Table 1 summarizes the result of this research.

Table 1. Data obtained in this research is compared to Stevens and Burley data [1]

\begin{tabular}{lcc}
\hline Item & $\begin{array}{l}\text { Data derived in } \\
\text { this research }\end{array}$ & $\begin{array}{c}\text { Stevens and } \\
\text { Burley data }\end{array}$ \\
\hline NPD projects & 138 & No data \\
Submitted ideas & 1125 & 300 \\
Small efforts / patent submissions & 192 & 125 \\
Launched products (Successful solutions) & 32 & 1.7 \\
Rejected solutions & 38 & N/A \\
\hline
\end{tabular}

As can be seen from Table 1, TRIZ provides a much more efficient NPD process than the regular NPD used in industry. This can be characterized by the success rate at different NPD stages, i.e. by the percentage of submitted ideas and solutions invested with some 'small effort' that resulted in launched products, as shown in Fig. 1. 
In addition to the calculated success rate of different NPD steps, Fig. 1 also shows the success rate of TRIZ-consulting projects in general.

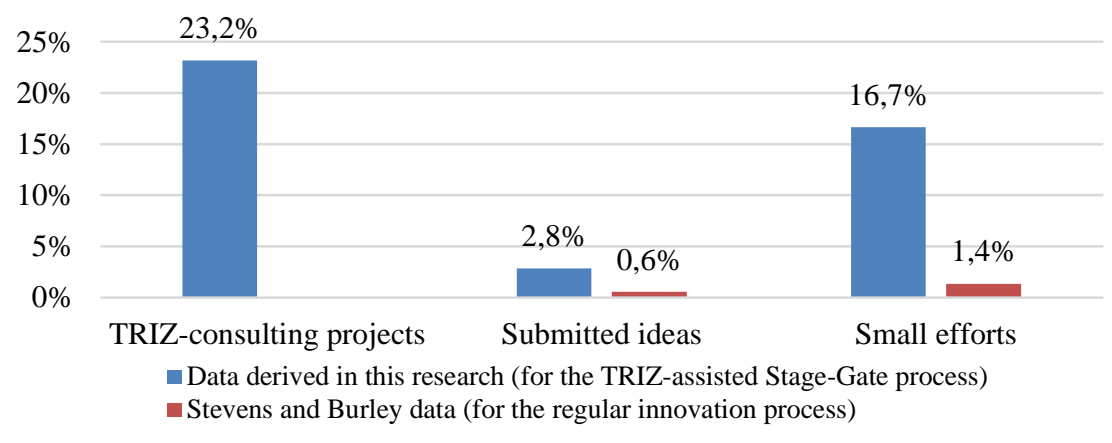

Fig. 1. Success rate at different NPD stages (calculated using the data from Table 1)

Fig. 2 represents the distribution of the 32 successful and 38 unsuccessful solutions within the QEA Business Cube, which was determined in the same manner as in our previous paper [18] that can be referred to for the details of this procedure.

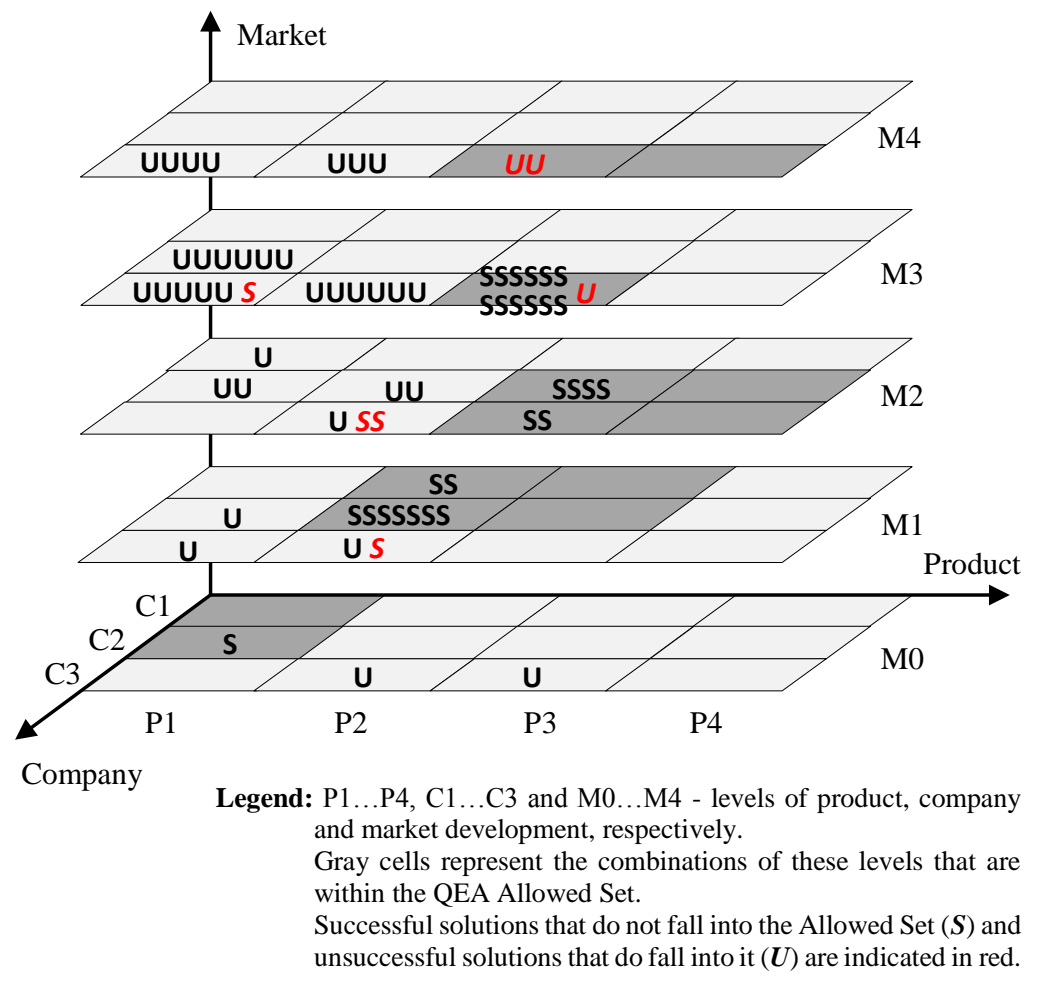

Fig. 2. Distribution of 32 successful (S) and 38 unsuccessful (U) solutions across the levels of the product, company and market development within the QEA Business Cube. 
Fig. 2 shows that

- Out of 32 successful solutions, 28 fall into the QEA Allowed Set and only 4 do not;

- Out of 38 unsuccessful solutions, only 3 fall into the Allowed Set, while the rest 35 do not.

\section{Discussion}

As can be seen from Fig.1, the modern TRIZ applied in the TRIZ-assisted Stage-Gate process for NPD is an order of magnitude more efficient than the regular NPD process with regard to the number of small efforts needed to launch one product. This confirms the results obtained in our previous paper [16].

The results of many projects analyzed in this research are, however, not known to the authors. Therefore, there is a possibility that some solutions resulting from these projects have actually been implemented by the clients, or their implementation is still in progress, which is quite likely for recent projects. This means that the number of successful solutions and successful projects may be higher than estimated in this paper. Therefore, the effectiveness of TRIZ evaluated by the method used in this paper should be considered a 'pessimistic estimation', while the actual effectiveness of modern TRIZ may be much higher.

In addition, it is important to note that all solutions, including those rejected by clients, were substantiated and proven technically feasible at the end of each project analyzed. The clients appreciated and accepted all of these solutions, but later rejected some of them for non-technical reasons.

As shown by the authors in a recent paper [18], while clients rejected a few solutions for personal or other subjective reasons, most solutions were rejected because they were unpromising in terms of business impact. Such solutions could have been rejected early in the project by the TRIZ team if the new TRIZ tool called 'QEA-based screening' [17] had been employed.

For this reason, the authors believe that using this tool may further increase the effectiveness of modern TRIZ.

For example, based on Fig. 2, we can conclude that if QEA-screening had been used in the 138 projects considered in this paper, then out of 70 solutions analyzed only 28 successful solutions and 3 unsuccessful solutions would have been delivered to the clients, while the other 35 unsuccessful solutions and 4 successful solutions would have been discarded before delivery. This, then, would have saved the money and effort spent on developing 39 solutions, most of which were eventually rejected by the client.

It seems fair to assume that:

1. In real projects, the solutions rejected according to QEA will be replaced by others that pass QEA-screening, and

2. The success rate of promising solutions that pass QEA-screening will be about the same, as can be determined from Fig. 2, i.e. about 28 out of 31 solutions (approximately $90 \%$ of solutions) will be successful. 
Under these assumptions, if the 39 solutions that did not pass QEA screening in this research were substituted by potentially successful solutions, then the overall success rate of 138 TRIZ consulting projects in Fig. 1 could be increased from $23.2 \%$ to about $46 \%$.

Opponents might argue that QEA-screening (1) rejects some potentially successful solutions that do not fall into the allowed set, resulting in a loss of profit that these solutions would generate, and (2) still delivers some potentially unsuccessful solutions that fall into the Allowed Set.

In this research, however, we did not find a confirmation to this concern because:

- All 4 successful solutions that did not fall into the Allowed Set in Fig. 2 yielded a launched product only after a very long development process: when the product reached the next stage of its evolution and/or the market for the product became more mature. So, these solutions can be considered successful only with some reservations because they required far much effort and money before launching a product.

- All 3 unsuccessful solutions that fall into the Allowed Set in Fig. 2, were unsuccessful only for subjective reasons: in 2 cases clients decided to abandon the developed solutions and focus on some other products; in one case the client was technically unable to implement the proposed solution, although we delivered a working prototype of the product. In fact, all of these solutions could have been successful and should not have been rejected.

\section{Conclusions}

The results presented in this paper confirm the results reported in a previous paper [16]. The research shows that the effectiveness of modern TRIZ in the TRIZ-assisted StageGate NPD process is at least ten times higher than the regular innovation process, and about $23 \%$ of TRIZ-consulting projects result in a launched product (pessimistic estimation).

The new TRIZ tool 'QEA-screening' may help to reduce the number of generated solutions that are unpromising businesswise, thus further increasing the effectiveness of modern TRIZ and the success rate of TRIZ-consulting projects (in terms of percentage of projects that yield a launched product) to about $46 \%$ or even higher.

\section{Acknowledgements}

The authors would like to thank Deborah Abramov for her helpful comments and for editing this paper. 


\section{References}

1. Stevens, G., Burley, J.: 3,000 raw ideas equals 1 commercial success! Journal of Research Technology Management 40(3), 16-27 (1997). doi:10.1080/08956308.1997.11671126

2. Steube, F.: The innovation funnel - infographic. A post on Twitter, March 4, 2018. Available: https://twitter.com/steube/status/970318101425393664, last accessed April 15, 2019.

3. Dam, R., Siang, T.: Stage 3 in the Design Thinking process: Ideate. [Online]. Available via Interaction Design Foundation website: https://www.interaction-design.org/literature/article/stage-3-in-the-design-thinking-process-ideate, last accessed April 15, 2019.

4. Boyd, D., Goldenberg, J.: Inside the box: a proven system of creativity for breakthrough results. Simon \& Schuster, New York (2013).

5. Abramov, O.: TRIZ-assisted Stage-Gate process for developing new products. Journal of Finance and Economics 2(5), 178-184 (2014). doi:10.12691/jfe-2-5-8

6. Filmore, P., Thomond, P.: Why reinvent the wheel? The efficacy of systematic problem solving method TRIZ and its value for innovation in engineering and its implications for engineering management. The TRIZ Journal, August 12, 2006. [Online]. Available: https://triz-journal.com/reinvent-wheel-efficacy-systematic-problem-solving-method-trizvalue-innovation-engineering-implications-engineering-management/, last accessed April $15,2019$.

7. Harlim, J., Belski, I.: On the effectiveness of TRIZ tools for problem finding. Procedia Engineering 131, $892-898$ ( 2015 ). doi:10.1016/j.proeng.2015.12.400

8. Spreafico, C., Russo, D.: TRIZ industrial case studies: a critical survey. Procedia CIRP 39, 51 - 56 ( 2016 ). doi: 10.1016/j.procir.2016.01.165

9. Ramadurai, B.: TRIZ case studies. Blog on the Internet, April 04, 2017. Available: http://balaramadurai.net/blog/2017/04/04/TRIZ-case-studies/, last accessed April 15, 2019.

10. RMIT University website. "Case studies. TRIZ repository." Available: https://www.edisons21.com/content/case-studies, last accessed April 15, 2019.

11. Applied Innovation Alliance website. "AIA case studies briefings Part 1." Available: https://www.appliedinnovationalliance.com/member-navigation/aia-case-studies-briefingspart1/, last accessed April 15, 2019.

12. Ilevbare, I., Phaal, R., Probert, D., et al.: Integration of TRIZ and roadmapping for innovation, strategy, and problem solving: Phase 1 - TRIZ, roadmapping and proposed integrations. Report on a collaborative research initiative between the Centre for Technology Management, University of Cambridge, UK, and Dux Diligens, Mexico, July 2011. Available via Institute for Manufacturing (IfM): https://www.ifm.eng.cam.ac.uk/uploads/Research/CTM/Roadmapping/triz_dux_trt_phase1_report.pdf, last accessed April 15, 2019.

13. Abramov, O.: 'Voice of the Product' to supplement 'Voice of the Customer'. In: Proceedings of TRIZFest-2015 Conference, pp. 313-321. Seoul, South Korea. Available: https://matriz.org/wp-content/uploads/2012/07/TRIZfest-2015-conference-Proceedings.pdf, last accessed April 15, 2019.

14. Malinin, L.: The method for transforming a business goal into a set of engineering problems. International Journal of Business Innovation and Research 4(4), 321-337 (2010). doi:10.1504/IJBIR.2010.033350

15. Litvin, S.: Main Parameters of Value: TRIZ-based tool connecting business challenges to technical problems in product/process innovation. Keynote presentation at 7th Japan TRIZ Symposium, September 9, 2011, Yokohama, Japan. [Online]. Available: http://www.trizjapan.org/PRESENTATION/sympo2011/Pres-Overseas/EI01eS-Litvin_(Keynote)110817.pdf, last accessed April 15, 2019. 
16. Abramov, O., Markosov, S., Medvedev, A., Rychagov, V.: Innovation funnel of modern TRIZ: experimental study to show the efficacy of the TRIZ-assisted Stage-Gate process. In: Proceedings of the 14th MATRIZ TRIZfest-2018 International Conference, pp. 105-110. Lisbon, Portugal. Available: https://matriz.org/wp-content/uploads/2019/01/TRIZfest2018-Proceedings.pdf, last accessed April 15, 2019.

17. Abramov, O.: Generating New Product Ideas with TRIZ-derived 'Voice of the Product' and Quantum-Economic Analysis (QEA). Journal of the European TRIZ Association, INNOVATOR 2(04), 80-87 (2017). Available: http://www.etria.eu/innovator/ETRIAjournal2017vol04.pdf, last accessed April 15, 2019.

18. Abramov, O., Markosov, S., Medvedev, A.: Experimental Validation of Quantum-Economic Analysis (QEA) as a Screening Tool for New Product Development. In: Koziołek S., Chechurin L., Collan M. (eds) Advances and Impacts of the Theory of Inventive Problem Solving, pp. 17-25. Springer, Cham (2018). doi:10.1007/978-3-319-96532-1_2 